\title{
Knowledge Crystallisation Supported by the KnowCat System
}

\author{
Ruth Cobos \\ Universidad Autónoma de Madrid \\ Spain
}

\section{Introduction}

Nowadays, it is commonly accepted that the World-Wide Web is the most popular tool for sharing knowledge and information (Berners-Lee, 1996). However, there is a huge and growing amount of information and it is getting more and more difficult to make sense out of it. The research work presented in this paper is an effort to address this Overload Information problem (Gross, 1964).

The main proposal of this work consists in managing the knowledge of a user community by means of a mechanism for knowledge construction in a distributed and incremental way. More specifically, knowledge evolves towards a structured and refined state by means of user interactions.

The aim of this mechanism is to achieve the crystallisation of user community knowledge as a result of user interactions, and without the need of an editor or manager of this task. The crystallised knowledge is the most accepted one by the community and, on the other hand, the knowledge that has not obtained enough acceptation will be likely to be removed.

It is important to highlight that knowledge is constantly evolving. Even crystallised knowledge may receive interactions from the community for further improvement. The key point is the evolution and improvement of knowledge by means of user evaluation.

The user community knowledge is subject to a maturation process involving two main phases. At first, due to the lack of critical mass of knowledge and interaction, a steering committee needs to be in charge of knowledge evaluation. Once enough mass is reached, knowledge crystallisation turns to be based on the evaluation performed by virtual communities of experts.

Those users who have added knowledge that has been crystallised are considered as experts, that is, their work have been recognised by the rest of the community. Virtual communities of experts are constructed in terms of sub areas of knowledge community, and they are in charge of the collaborative evaluation of the knowledge of their sub areas. This is similar to the peer review mechanism.

A collaborative Knowledge Management system called KnowCat has been designed and implemented ("Knowledge Catalyser"). KnowCat is based on the concept of Knowledge Crystallisation, supported by virtual communities of experts. KnowCat allows a user community to share, evaluate and structure collective knowledge. The system allows 
building Web sites where relevant and structured knowledge about some area or topic can be found (Cobos, 2003).

The KnowCat system is presented in the Section 2. Its Knowledge Crystallisation mechanism is detailed in Section 3. The system has evolved for the last twelve years, during this period it has been used with several user communities and a great amount of research data and results have been obtained, which are presented in Section 4. Finally, this paper concludes with some conclusions and future works in Section 5.

\section{The KnowCat system}

KnowCat (acronym for "Knowledge Catalyser") is a fully consolidated and thoroughly tested and validated Knowledge Management system which has been developed at Universidad Autónoma de Madrid (Spain) an in active use since 1999 (Alamán and Cobos, 1999; Cobos, 2003).

\subsection{The characteristics of the KnowCat community knowledge}

KnowCat enables us to build up community knowledge sites or knowledge areas. Each knowledge site is divided into three workspaces:

- Community knowledge workspace, which shows the knowledge elements contributed by the users.

- Communication community space, which supports the communication among the users through e-mail lists.

- Personal user workspace, a workspace in which each user can see their own contributions to the knowledge site and can receive information about the interactions of other users related to their contributions.

More specifically, the community knowledge is organised around several knowledge elements. These knowledge elements and the relationships among them are shown in figure 1 .

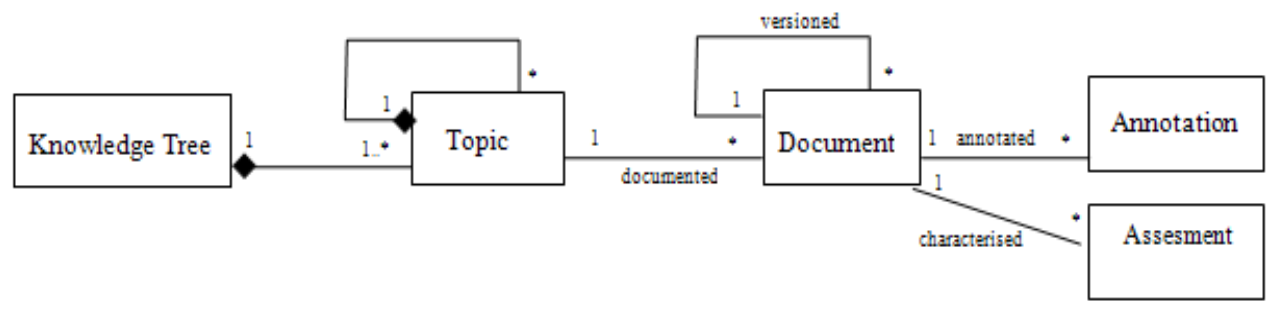

Fig. 1. KnowCat knowledge elements

Firstly, the knowledge tree, which is a hierarchical structure of topics, displays the organisation of the knowledge site in several topics.

Secondly, each topic contains a set of mutually alternative documents that describe the topic. At any given time, all documents contained in the same topic compete with each other 
to be considered as the "best" description of the topic. This competitive environment is achieved by the Knowledge Crystallisation mechanism of the system, which is supported by virtual communities of users. Furthermore, each document has a "crystallisation degree", which determinates the social acceptation of this one for the user community (more details in Section 3). At any time, the author of a document can contribute with a new version of his/her document.

Thirdly, each document can receive annotations -or note, for short-. A note is a review about the information presented in a document. Each note has a type that determinates its purpose. We have the following note types:

a. "Clarification" note: this is useful to clarify some parts of the document. E.g. "The following link, that it appears in my document, it doesn't work now, but it worked a week ago ...".

b. "Support" note: this is useful to express agreement with the document. E.g. "This document is very useful in my opinion and it is easy to read it".

c. "Review" note: this is useful to make suggestions about adding, removing, or changing some parts of the document, or for making comments regarding it. More specifically, we have the following note types:

i. "Addition" note: to suggest additions to the document. E.g. "In my opinion, it is necessary to add in this document an index with its most important sections".

ii. "Delete" note: to suggest deletions from the document. E.g. "In the summary there are some examples which, may be, are not necessary".

iii. "Correction" note: to suggest changes to the document. E.g. "I think that there is an error in the first paragraph of the conclusion section, it appears 'motor' instead of 'motivation'".

iv. "Criticism" note: to criticise the document. E.g. "...Moreover the arguments are not properly in our opinion in order to justify author position".

v. "Question" note: to make open questions about the document. E.g. "I think that the document author didn't express clearly his opinion about the document topic, please, can you give us your opinion in the next document version?".

Finally, each document can receive assessments. An assessment represents a "weight assertion" which can be used by the users in order to determinate how good (with a value from 1, minimum value, to 10, maximum value) a specific aspect (i.e. correctness, innovation, etc.) of a specific part of a document (i.e. introduction, references, etc.) is. E.g. References.Completeness $=9$ (Part.Aspect=value) means that a specific document, in the opinion of the user, has the $90 \%$ of appropriated references (i.e. some few number of references are missing in this document).

\subsection{The collaborative work supported by KnowCat at the community knowledge workspace}

The KnowCat users can collaborate in a knowledge site trough the following potential interactions: modifying the knowledge tree, adding a document to a selected topic, voting a document, annotating and contributing with assessments about a document, adding a document version, accessing to documents and document versions, accessing to notes and assessments.

In figure 2, we can see an example screenshot of the community knowledge workspace of "Technical Office" KnowCat site. 


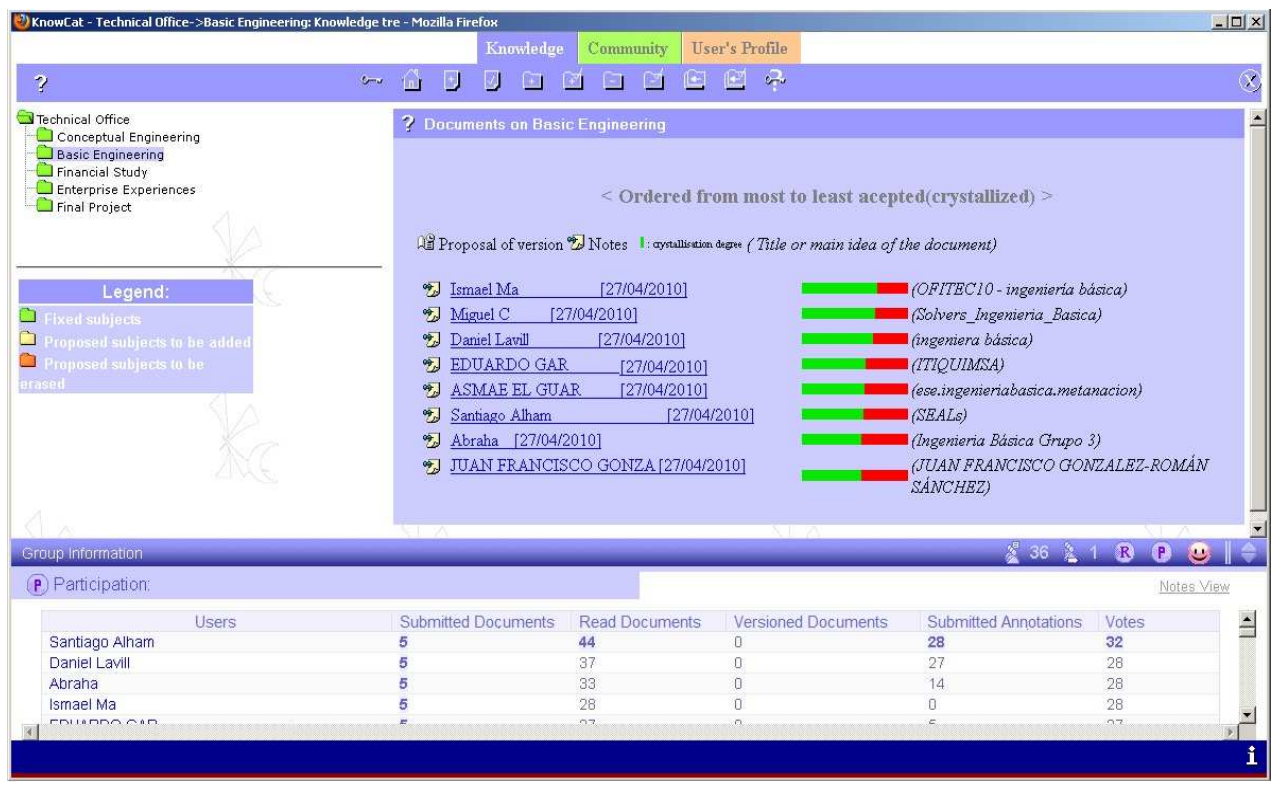

Fig. 2. KnowCat example screen of a knowledge site about "Technical Office".

The details of the user operations provided by KnowCat are:

a. Modifying the knowledge tree, which is displayed on the left side of the screen in Figure 2. The user can participate in the collaborative construction of the knowledge tree. They can suggest adding, deleting or modifying topics of the knowledge tree.

b. Adding a new document to a selected topic. A user contributes with a document (normally a Web page located in a Web server) related to a specific topic of the knowledge tree. From this moment on, the document can receive votes from other users, notes and assessments (normally from other users) and a revised version from the original author. As seen on right side of the screen in Figure 2, the documents are identified by the author's name, arrival date and title. They are ordered by their crystallisation degree, which is shown to the right of the identification heading of each document (with the green-red bar). On the left side of the identification heading of each document are the icons indicating whether a document has received notes and assessments and whether a new version of the document is available. For example, the document identified by "Ismael Ma [27/04/2010] (OFITEC10 - ingeniería básica)" shows the highest crystallisation degree in the topic called "Basic Engineering".

c. Displaying the content of a document (accessing to a document). When a topic is selected from the knowledge tree (it is displayed on the left of the screen) the identification of its documents are shown on the right of the screen. A user can display the content of a document by clicking its identification. The document is then displayed on the right side of the screen.

d. Voting a document. A user can express with a vote the degree to which s/he is in agreement with a document. There are two types of voting mechanisms available in KnowCat: i) a value from a range (1-5, where 1 is the minimum value and 5 the maximum one) and ii) with the single value " 1 " to denote agreement with the 
document. The latter is by far the most popular voting mechanism in the system and has been validated as the most useful way of expressing agreement with a document.

e. Adding an annotation to a document. A user contributes a note to a document in order to make suggestions and/or give comments or opinions. It is possible to annotate a specific document when displayed on the screen. In order to use this operation, a user has to contribute with the following: i) a text, which expresses the assistance that the user wants to provide to the author of the annotated document and ii) a note type (see previous section).

f. Adding assessments to a document: A user contributes with assessments to a document at the same time that $\mathrm{s} / \mathrm{he}$ is annotating it. In order to use this operation, a user has to contribute with the following: i) select an element of the document (i.e. introduction, references, etc.), ii) select an aspect to evaluate (i.e. correctness, innovation, etc.) of the selected element (i.e. introduction, references, etc.) and iii) a value from 1 to 10 (1 minimum value, 10 maximum value).

g. Displaying the content of a note and the content of assessments. When the content of a document is displayed, it is possible to access the list of its received notes and assessments on the left side of the screen.

h. Adding a new version of a document. The author of a document can contribute with a new version of her/his document at any time. This operation is available as a sub-case of the "Adding document" operation.

i. Displaying the content of a new document version. When the content of a document, which is versioned, is displayed, it is possible to select to display its proposed new version.

\subsection{Virtual communities and knowledge evolution}

A virtual community (Schlichter et.al., 1998) is a group of users that are considered experts in one or more related topics. In this work the opinions from experts are important because they should have more impact than opinions from novices or occasional users.

Virtual communities of experts are constructed in terms of the knowledge tree. For each topic, the community of experts in this topic is composed of the authors of the crystallised documents on the topic, on the parent of the topic, on any of the children of the topic or on any of the sisters of the topic. There is a virtual community for each topic of the knowledge tree, and any successful author usually belongs to several related communities.

When it is started a knowledge area there is only a root node with the main topic. Probably, there will not be enough people and interactions to make the knowledge crystallisation mechanism credible. In relation with this bootstrapping problem, virtual communities have also proven to be handful. Virtual communities behave in a different way when they are just beginning. So, it is proposed a maturation process that involves several phases. Figure 3 shows this evolution.

At the beginning stages the user community work in a "supervised" mode. During this supervised phase there will be a steering committee in charge of proposing knowledge structures (initial refinements of the root node) and voting for them. The members of the steering committee are defined in the moment of creation of the knowledge area; new members can be added by consensus of the current members. 
In this phase, descriptions (documents about some topic) may be added to the system both by the members of the steering committee and by other users that are considered as collaborators. However, only the members of the steering committee have the complete capability of voting on the documents, and thus in deciding which documents crystallise. Collaborators may have limited capability of voting, if the steering committee decides so.

\begin{tabular}{|c|c|}
\hline NEW KNOWLEDGE AREA & It is created a new knowledge area. \\
\hline UPERVISED PHASE & $\begin{array}{l}\text { There is a "steering committee" in charge of many of the } \\
\text { decisions that is distributed in later phases. For example, they } \\
\text { will decide on the way knowledge is structured. }\end{array}$ \\
\hline $\begin{array}{l}\text { The steering committee may } \\
\text { decide to promote the } \\
\text { knowledge area to the Active } \\
\text { stage, when the knowledge tree }\end{array}$ & $\begin{array}{l}\text { The community may decide to return to supervised stage } \\
\text { to engage in a process of re-structuration the knowledge } \\
\text { tree of the knowledge area. }\end{array}$ \\
\hline CTIVE PHASE & $\begin{array}{l}\text { There is a lot of activity about the contents of the knowledge } \\
\text { area, that is, new knowledge in form of fragments or }\end{array}$ \\
\hline $\begin{array}{l}\text { After some time, many of } \\
\text { the members of the original } \\
\text { community cease to be } \\
\text { active. }\end{array}$ & $\begin{array}{l}\text { descriptions of topics is arrived. Knowledge Crystallisation is } \\
\text { Contributions rate increases. There are many active } \\
\text { community members again. }\end{array}$ \\
\hline TABLE PHASE & $\begin{array}{l}\text { There are few changes. Most of activity is consultation and few } \\
\text { contributions arrive. }\end{array}$ \\
\hline
\end{tabular}

Fig. 3. Knowledge evolution of a knowledge area

Eventually, the steering committee may decide to advance the area of knowledge to the "active" mode, possibly when a critical mass of participants and interactions is achieved. In this moment there should be a single tree structure for the area, decided by consensus. Then the steering committee is dissolved and the subsequent crystallisation of the knowledge is based on virtual communities.

During the "active" phase, when one user contribution crystallises, s/he receives a certain amount of "votes" that s/he may apply for the crystallisation of other documents (of other authors) in the virtual community where her/his crystallised document is located. As in the previous phase the descriptions may be added both by experts and collaborators; in fact all users start using the system as collaborators and when a document of a user crystallises s/he becomes an expert in related communities of the topic where the document is located.

The other aspect of knowledge crystallisation is the evolution of the structure of the knowledge tree. If a member of a virtual community proposes to add a new subject to a topic, remove a subject from a topic or move a subject from one topic to another topic, then a minimum quorum of positive votes from other members of the community will be necessary for the change to be made. 
Finally, an active community may reach the "Stable" phase. Many of the community members are not active any longer, so different rules should be applied to ensure some continuity of the crystallisation. Changes are rare, and most of the activity is consultation. Few new contributions arrive, and they will have much more difficulties to crystallise comparing to the previous phase. However, if activity raises to a minimum again, the node may switch to "Active" status, and engage in a new crystallisation phase.

\section{Knowledge crystallisation}

A central concept in this work is the "Knowledge Crystallisation" mechanism. With this mechanism it could be possible to have, in each moment, the best knowledge elements in a knowledge area, in opinion of the user community.

The mentioned KnowCat knowledge elements -documents, notes, version documents, topics- are produced by the users and their lifetime depends on the patterns of their usage. Any of these elements will stay longer in the knowledge area if it is frequently used and receive favourable opinions from other users. In that case, its crystallisation degree will rise, and thus its probability to stay in the knowledge area. However, if one knowledge element is not used or it doesn't receive favourable opinions by the users, then it will eventually disappear from the knowledge area as a consequence of its crystallisation degree going down. This mechanism is called Knowledge Crystallisation.

Firstly, it is shown in the next section the crystallisation of documents. Secondly, it is shown the crystallisation of annotations, and version documents. Finally, it is shown the crystallisation of the structure.

\subsection{Documents' crystallisation process}

The Knowledge Crystallisation mechanism takes into account the users' opinions about the documents and the evolution of its received opinions in order to determinate which documents have enough acceptation during a determinate period of time. They will then crystallise.

Each document has a value called "crystallisation degree" or "social acceptation degree"-or acceptation degree, for short-, which is a value between 0-1. A document "crystallise" when his acceptation degree stay for a period of time called "time for crystallising", e.g. 2 weeks, over a determinate "crystallisation point" , e.g. 0.65 .

The acceptation degree of a document takes into account:

- The explicit received opinions concerning the document are computed in the ExplicitAcceptationDegree value. These explicit opinions are: the received votes (ratings) and how theses votes have been received; and the received assessments, notes and their types.

- The implicit received opinions concerning the document are computed in the ImplicitAcceptationDegree value. These implicit opinions are the accesses to the document.

The acceptation degree, which is called as AcceptationDegree, of each document, doc , in a concrete moment, $t_{j}$, is calculated from the mentioned elements in the following way:

It is considered that the explicit opinions are more useful in order to determinate the acceptation of a document, because they are more elaborated opinions that implicit opinions, so the $\operatorname{coef}_{E}$ is higher than $\operatorname{coef}_{I}\left(\mathrm{e} . \mathrm{g} \cdot \operatorname{coef}_{E}=0.9 ; \operatorname{coef}_{I}=0.1\right)$. 


$$
\text { AcceptationDegree }\left(\text { doc }_{i}, t_{j}\right)=\left[\begin{array}{l}
\text { ExplicitAcceptationDegree }\left(\text { doc }_{i}, t_{j}\right) \times \operatorname{coef}_{E}+ \\
\text { Im plicitAcceptationDegree }\left(\text { doc }_{i}, t_{j}\right) \times \operatorname{coef}_{I}
\end{array}\right] \times \operatorname{History}\left(\text { doc }_{i}, \text { versionDoc }_{i}, t_{j}\right)
$$

The knowledge crystallisation mechanism deals with knowledge in evolution. The documents evolves through a sequence of document versions, how is this evolution is calculated in the "history degree" value, i.e. History $\left(\right.$ doc $_{i}$, versionDoc $\left._{i}, t_{j}\right)$. This value is used in the calculation of the acceptation degree of a document in order to correct its social acceptation taking into account its evolution through several document versions. See Section 3.2.

The first idea in order to calculate the ImplicitAcceptationDegree of a selected document $d o c_{d}$ is to compare the number of the received access by $d o c_{d}$ with the received access by all the documents that are in the same topic that $d o c_{d}$.

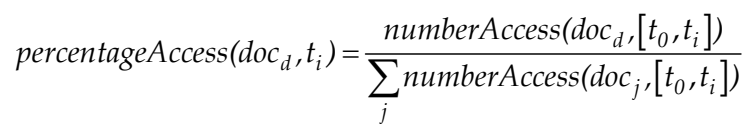

where,

$t_{0}$ the moment when the knowledge area was created.

$t_{i}$ the actual moment.

numberAccess $\left(\operatorname{doc}_{d},\left[t_{0}, t_{i}\right]\right)$ is the number of received access by doc $c_{d}$ from $t_{0}$ to $t_{i}$.

$d o c_{j}$ is a document which is in the same topic than $d o c_{d}$.

This measurement needs to be normalised because it is depends of the context where the document is located, so it is proposed the Formula 3 in order to obtain the implicit social acceptation degree of a document $d o c_{d}$.

$$
\operatorname{Im} \text { plicitAcceptationDegree }\left(\operatorname{doc}_{d}, t_{i}\right)=\frac{\operatorname{percentageAccess}\left(d o c_{d}, t_{i}\right)}{\max \left(\text { percentageAccess }_{\left.\left(d o c_{j}, t_{i}\right)\right)}\right.}
$$

where:

$\max \left(\right.$ percentageAccess $\left.\left(\operatorname{doc}_{j}, t_{i}\right)\right)$ is the highest percentage of the received access from the document which are in the same topic than $d o c_{d}$.

The explicit social acceptation degree of $d o c_{d}$ is calculated taking into account the following values: the value concerning the received votes, ExplicitAcceptationDegree_Votes, the value concerning the received notes, ExplicitAcceptationDegree_Notes, and the value concerning the received assessments, ExplicitAcceptationDegree_Assessments.

$$
\text { ExplicitAcceptationDegree }\left(\text { doc }_{d}, t_{i}\right)=\left[\begin{array}{l}
\text { ExplicitAcceptationDegree_Votes }\left(\text { doc }_{d}, t_{i}\right) \times \operatorname{coef}_{E V}+ \\
\text { ExplicitAcceptationDegree_Notes }\left(\text { doc }_{d}, t_{i}\right) \times \operatorname{coef}_{E N}+ \\
\text { ExplicitAcceptationDegree_Assessments }\left(\text { doc }_{d}, t_{i}\right) \times \operatorname{coef}_{E A}
\end{array}\right]
$$

It is proposed that $\operatorname{coef}_{E V}$ is higher than $\operatorname{coef}_{E N}$ and $\operatorname{coef}_{E A}$, because the votes are realised by expert users while every community user can realise notes and assessments (e.g. $\operatorname{coe} f_{E V}=0.8$; $\operatorname{coef}_{E N}=0.1 ; \operatorname{coef}_{E A}=0.1$.

The ExplicitAcceptationDegree_Votes of $d o c_{d}$ is calculated taking into account the normalised percentage of the received votes by $d_{0} c_{d}$, normalPercentageVotes, and a value concerning how theses votes have been received in time by it, i.e., the evolution of the number of received votes in time, evolution Votes. 


$$
\text { ExplicitAcceptationDegree_Votes }\left(\operatorname{doc}_{d}, t_{i}\right)=\text { normalPercentageVotes }\left(\operatorname{doc}_{d}, t_{i}\right) \times \operatorname{evolutionVotes}\left(\text { doc }_{d}, t_{i}\right)
$$

where,

$$
\begin{gathered}
\text { normalPercentageVotes }\left(\operatorname{doc}_{d}, t_{i}\right)=\frac{\text { percentageVotes }\left(d o c_{d}, t_{i}\right)}{\max \left(\text { percentageVotes }\left(d o c_{j}, t_{i}\right)\right)} \\
\text { percentageVotes }\left(d o c_{d}, t_{i}\right)=\frac{\text { numberVotes }\left(d o c_{d},\left[t_{0}, t_{i}\right]\right)}{\sum_{j} \text { numberVotes }\left(d o c_{j},\left[t_{0}, t_{i}\right]\right)}
\end{gathered}
$$

evolutionVotes is a value in the rank 0.95-1.10 when $d o c_{d}$ has a good evolution of the number of the received votes in time, e.g. $d o c_{d}$ receives constantly votes. However, evolution Votes is a value in the rank 0.80-0.95 when $d o c_{d}$ has a bad evolution, e.g. doc $c_{d}$ received at the beginning a lot of votes but close to $t_{i}$ it doesn't receive new votes.

ExplicitAcceptationDegree_Notes of $d o c_{d}$ is calculated taking into account on the one hand the received "support" annotations and on the other hand the received "review" annotations.

$$
\text { ExplicitAcceptationDegree_Notes }\left(\operatorname{doc}_{d}, t_{i}\right)=\left[\begin{array}{l}
\text { normalPercertageSupportNotes }\left(\text { doc }_{d}, t_{i}\right) \times \operatorname{coef}_{S A}+ \\
\text { normalPercertage Re viewNotes }\left(\text { doc }_{d}, t_{i}\right) \times \operatorname{coef}_{R A}
\end{array}\right]
$$

where,

normalPercentageSupportNotes $\left(\operatorname{doc}_{d}, t_{i}\right)$ is the normalised percentage of the received "support" notes by $d_{0} c_{d}$ until the moment $t_{i}$.

normalPercentageReviewNotes $\left(\right.$ doc $\left._{d}, t_{i}\right)$ is the normalised percentage of the received "review" notes by $d o c_{d}$ until the moment $t_{i}$.

It is proposed that $\operatorname{coef}_{S A}=1$ and the following function is used in order to calculate the coefficient $\operatorname{coef}_{R A}$. With this function the following two cases are distinguished: if a document receives few "review" notes means that this document has social interest and $\operatorname{coef}_{R A}$ is close to value 1; if it receives a lot of "review" notes means that the document needs to be improved and $\operatorname{coef}_{R A}$ has a value close to 0 .

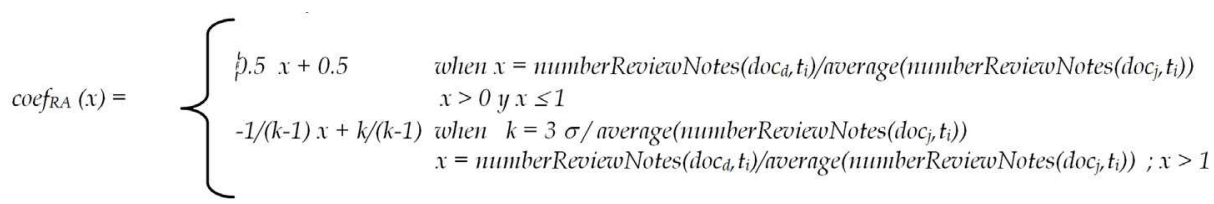

ExplicitAcceptationDegree_Assessments of $d c_{d}$ is calculated taking into account the normalised average value of the received assessments.

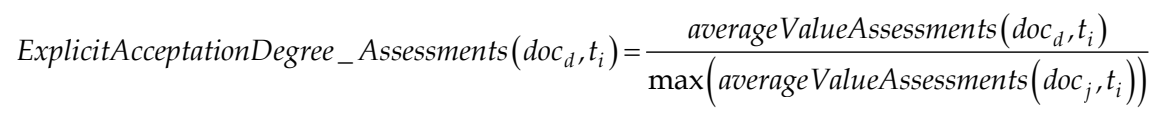

where,

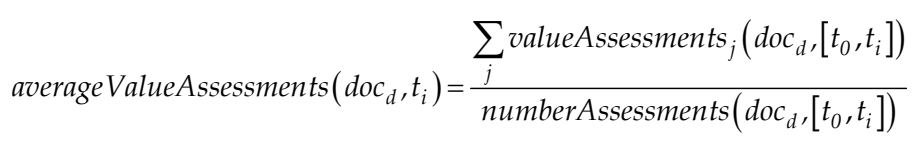


valueAssessments ${ }_{j}\left(d o c_{d},\left[t_{0}, t_{i}\right]\right)$ is the value of the assessments identified as $j$ for the $d o c_{d}$.

\subsection{Notes and document versions' crystallisation process}

As it is shown in the previous section, a social accepted document can "crystallise", however a social accepted annotation can "stay" in the knowledge area and a social accepted proposal of a document version can "consolidate".

The annotations receive votes, too. These votes can be "in favour" or "against" the annotation. The knowledge crystallisation mechanism calculates per annotation the number of the received votes of each type in this way:

$$
\text { AgainstDegree }\left(\text { note }_{a}, t_{i}\right)=\text { numberVotesAgainst }\left(\text { note }_{a}, t_{i}\right)-\text { numberVotesInFavour }\left(\text { note }_{a}, t_{i}\right)
$$

If AgainstDegree of a selected annotation note ${ }_{a}$ is higher than the average of received votes by the annotations which are in the same location as note $e_{a}$ then this annotation is delete from the knowledge area, in another case the annotation "stay" in the knowledge area.

The documents' assessments don't receive votes, therefore, they don't have a crystallisation mechanism associated.

In each moment, it is possible to have a proposal of a new document version, versionDoci, of a document, doci. The knowledge crystallisation mechanism determinates when a new document version replaces the previous one, i.e., the new document version "consolidate". For this matter, the members of the virtual community of the topic of a document with a new proposal of version have to give their opinions about the following characteristics of the new document version:

- Continuity: that is, if the new document version deals the content of the previous one in a similar way.

- Improvement: that is, if the new document is an improvement of the previous one.

With the received opinions concerning the first characteristic is obtained the "continuity degree", ContinuityDegree, of the new document version (a value between 0-10, 10 the maximum value), with the received opinions concerning the second characteristic is obtained the "improvement degree", ImprovementDegree, of the new document version (a value between 0-10). If the continuity degree is higher than a determined value called "continuity point" (for example, 5) then the new document version replace the previous one. The history degree, which is used in Formula 1, is calculated as a function of the improvement degree as follows:

$$
\begin{aligned}
& \text { History }\left(\text { doc }_{i}\right. \text {, versionDoc } \\
& \left.i, t_{j}\right)=\text { funHistoryDoc }\left(\text { ImprovementDegree }\left(\text { versionDoc }_{i}, t_{j}\right)\right) \\
& \text { funHistoryDoc }(x)=\left\{\begin{array}{l}
0.02 * x+0.88 \text { when } x=\text { ImprovementDegree }\left(\text { versionDoc }_{i}, t_{j}\right), x \geq 0 \text { and } x<6 \\
0.05 * x+0.7 \text { when } x=\text { ImprovementDegree }\left(\text { versionDoc }_{i}, t_{j}\right), x \geq 6 \text { and } x \leq 10
\end{array}\right.
\end{aligned}
$$

\subsection{Structure's crystallisation process}

The last aspect of knowledge crystallisation is the evolution of the structure of the knowledge tree. If a member of a virtual community proposes to add a new subject to a topic, remove a subject from a topic or move a subject from one topic to another topic, then a 
minimum quorum of positive votes from other members of the community will be necessary for consolidating the change.

This minimum quorum, MinimumQuorum, of positive votes for a selected proposed change in the structure propChangeStructp is calculated as follows:

$$
\operatorname{MinimumQuorum}\left(\text { propChangeStruct }_{p}, t_{i}\right)=\left[\begin{array}{l}
\text { percentageExperts } \times \\
\text { numberActiveExperts }\left(\text { propChangeStruct }_{p}, t_{i}\right)
\end{array}\right]
$$

where,

percentageExperts is a configurable value, e.g. 0.8

numberActiveExperts is the number of active member of the virtual community where propChangeStruct is proposed.

\section{Research studies supported by KnowCat}

KnowCat has been tested for more than ten years in several research studies with student communities at Universidad Autónoma de Madrid (UAM, Spain), Universitat de Lleida (UdL, Spain) and Universidad Pontificia Bolivariana (UPB, Colombia), among others. Table 1 shows a summary of the participants' communites of these research studies.

Most of these research studies have corroborated these design hypotheses of KnowCat (Alamán \& Cobos, 1999; Cobos \& Alamán, 2002; Cobos, 2003; Cobos \& Pifarré, 2008; Diez \& Cobos, 2007; Gómez, Gutiérrez, Cobos \& Alaman, 2001):

- When a set of people having a certain level of knowledge engage in a reasonable interaction with the system, the result converges to some consensus. This consensus is closely related to an objective measurement of "quality" of the contributions.

- The knowledge classification through a tree structure has been exposed as a suitable approach for managing and organising the knowledge.

- The use of document annotations is useful for motivating document authors in generating new document versions. If a document author takes into account the received notes in the creation of a new document version of his/her annotated document, the new document version will improve.

- The knowledge area resulted by the user community interactions and the Knowledge Crystallisation mechanism represents the social interests of its community.

These research studies took the form of longitudinal case studies conducted in authentic university environments. In order to illustrate the research methodology of these studies, an example about how the system could be used for any community is exposed:

1. Both students and instructors supported the creation of a common frame of reference before using the KnowCat system. They shared the study's common values and pedagogical goals, and the collaborative tasks were coordinated in advance - i.e., the tasks and the timetable were agreed on previously between instructors and students. Moreover, the students, who needed it, received formation about how to use KnowCat features.

2. The main procedure of the students' work with the KnowCat system was as follows:

a. The students were distributed into the topics that were established by the instructor in the knowledge tree. Normally, there were between five to ten students 
working in the same topic. Individually, students read some information about a specific topic course.

b. The students wrote an individual report (document) about the topic and entered it into KnowCat. These reports contained a personal reflection on the content of the read information, or suggested a personal solution to a specific problem.

c. The students read some peers' report and annotated them -i.e. by giving assistance- in order to help the fellow classmates improve on it. For each individual topic, the students were asked to annotate a minimum number of classmate's report (e.g. to write at least three notes and to write at least five assessments, these notes and assessments could be done on one or more documents). During the study, the students were strongly encouraged to annotate the reports of different classmates. In most of the research studies, the students' documents received a different number of interactions, for instance, none of the students' documents received less than three notes. In some studies, the students voted for the best document on a topic. In this way, the knowledge crystallisation mechanisms could be started to generate an initial classification.

d. The document's author read the notes concerning her/his report, taking into account her/his classmates scaffolds, re-wrote the report and entered it back into the system again, as a new document version.

e. Finally the students voted for the best document on a topic. Moreover, they gave their opinions about the "continuity" and "improvement" characteristics of the new document versions (see Section 3.2) in order to facilitate the system the decisions over which documents had to be replaced with their new document version.

3. Students answered to a questionnaire about the work realised with KnowCat. In some cases, they were interviewed. To enable coding and analysing, the interviews were transcribed word by word.

4. The data analysis was generated by the instructors. Both a qualitative content analysis and a quantitative analysis were made about the students' contributions in the system. These analyses were useful in order to corroborate both the common mentioned system design hypotheses as specific ones formulated in the context of each specific research study (see some examples below).

Some specific research studies carried out with communities at UdL have contributed the following corroborated hypotheses (Pifarré \& Cobos, 2009; Pifarré \& Cobos, 2010):

- The pedagogical application of the KnowCat system may favour and improve the development of the students' metacognitive learning processes. The content analysis of the students' interviews revealed the existence of metacognitive knowledge regarding the learning processes that students develop while interacting with KnowCat knowledge elements. Students showed high levels of consciousness about learning new strategies and about the conditional use of these strategies to solve specific tasks efficiently.

- The instructional application of the KnowCat system may favour and improve the development of students' self-regulated skills. Small group interaction patterns appear while their members are working together throughout the instructional process supported by KnowCat. These interaction patters were related with an increasing number of self-regulated processes, specially planning, asking for clarification and monitoring skills. 


\begin{tabular}{|c|c|c|c|}
\hline COURSE & $\begin{array}{l}\text { ACADEMIC } \\
\text { YEARS }\end{array}$ & \begin{tabular}{|c|} 
\#PARTICIPANTS \\
PER YEAR
\end{tabular} & $\begin{array}{l}\text { DEPARTMENT, } \\
\text { UNIVERSITY }\end{array}$ \\
\hline Operating Systems & $\begin{array}{c}1998 / 1999- \\
2006 / 2007 \\
\text { (nine years) }\end{array}$ & 250 & $\begin{array}{l}\text { Computer Engineeting, } \\
\text { UAM }\end{array}$ \\
\hline Uncertain Reasoning & $\begin{array}{l}1999 / 2000- \\
2002 / 2003 \\
\text { (four years) }\end{array}$ & 15 & $\begin{array}{c}\text { Computer Engineeting, } \\
\text { UAM }\end{array}$ \\
\hline $\begin{array}{l}\text { Mathematics for } \\
\text { Children's Training }\end{array}$ & $\begin{array}{l}2000 / 2001- \\
2004 / 2005 \\
\text { (five years) } \\
\end{array}$ & 40 & $\begin{array}{c}\text { Theory of Education, } \\
\text { UAM }\end{array}$ \\
\hline Learning Strategies & $2002 / 2003$ & 31 & $\begin{array}{c}\text { Pedagogy and } \\
\text { Psychology, } \\
\text { UdL } \\
\end{array}$ \\
\hline $\begin{array}{l}\text { Psychopedagogy } \\
\text { Intervention }\end{array}$ & $2002 / 2003$ & 18 & $\begin{array}{l}\text { Pedagogy and } \\
\text { Psychology, } \\
\text { UdL }\end{array}$ \\
\hline Artificial Intelligence & $\begin{array}{l}2004 / 2005- \\
2007 / 2008 \\
\text { (four years) }\end{array}$ & 250 & $\begin{array}{c}\text { Computer Engineeting, } \\
\text { UAM }\end{array}$ \\
\hline $\begin{array}{l}\text { Automata Theory and } \\
\text { Formal Languages }\end{array}$ & $\begin{array}{c}\text { 2004/2005 - } \\
\text { 2006/2007 } \\
\text { (three years) }\end{array}$ & 90 & $\begin{array}{c}\text { Computer Engineeting, } \\
\text { UAM }\end{array}$ \\
\hline $\begin{array}{l}\text { Biology for } \\
\text { Development }\end{array}$ & $\begin{array}{c}\text { 2004/2005 - } \\
\text { 2006/2007 } \\
\text { (three years) } \\
\end{array}$ & 40 & $\begin{array}{l}\text { Biochemistry, } \\
\text { UAM }\end{array}$ \\
\hline Computers Systems II & $\begin{array}{c}2005 / 2006- \\
2006 / 2007 \\
\text { (two years) }\end{array}$ & 200 & $\begin{array}{c}\text { Computer Engineeting, } \\
\text { UAM }\end{array}$ \\
\hline $\begin{array}{l}\text { Psychopedagogy } \\
\text { Intervention in } \\
\text { children development } \\
\text { disorders }\end{array}$ & $2006 / 2007$ & 26 & $\begin{array}{l}\text { Pedagogy and } \\
\text { Psychology, } \\
\text { UdL }\end{array}$ \\
\hline Technical Office & $\begin{array}{c}2007 / 2008- \\
2009 / 2010 \\
\text { (three years) } \\
\end{array}$ & 35 & $\begin{array}{c}\text { Chemical Engineering , } \\
\text { UAM }\end{array}$ \\
\hline Collaborative Systems & $\begin{array}{l}2008 / 2009- \\
2010 / 2011 \\
\text { (two years) }\end{array}$ & 10 & $\begin{array}{c}\text { Computer Engineeting, } \\
\text { UAM }\end{array}$ \\
\hline $\begin{array}{l}\text { Technology } \\
\text { Management }\end{array}$ & $\begin{array}{c}2009 / 2010- \\
2010 / 2011 \\
\text { (two years) } \\
\end{array}$ & 15 & $\begin{array}{c}\text { Computer Engineeting, } \\
\text { UPB }\end{array}$ \\
\hline Informatics I & $2009 / 2010$ & 20 & $\begin{array}{l}\text { Law, } \\
\text { UPB }\end{array}$ \\
\hline
\end{tabular}

Table 1. Courses and participants in the realised research experiences. 
On the one hand, KnowCat system has been involved since the first system version in 1999 until nowadays, due to the results obtained and the users' opinions from all the research studies. Moreover, the system was extended with new services.

Firstly, a console with awareness services was added to KnowCat (Cobos, Claros \& MorenoLlorena, 2009). These services are: brief information about registered users (what have these users done?), brief information about connected users, a radar view (where and what are the connected users doing?), participation-meter (How many times have the registered users done each task?), a fish eye view (when, where and what has each registered user done?) and a map of interaction among users in the annotating task (who has annotated the document of whom?).

These new services provide users useful information about how KnowCat users are interacting with the system. This console is shown in the bottom part ("Group Information") of the KnowCat screen. In Figure 2, we can see the participation-meter service.

Secondly, in this mentioned console a motivation booster service was added, which provide users feedback information about its work progress in KnowCat (Echeverria \& Cobos, 2010). These extensions to the system have corroborated these hypothesis related to user community feelings:

- The users are aware of their participation in a collaborative work, in other words, they feel that are working in a collaborative way.

- When users receive feedback information about their activities progress, then they increase their interactions with the system performing their activities in a better manner, and they become more motivated to interact with the system.

On the other hand, a prototype called Semantic KnowCat (SKC) was developed on KnowCat to investigate solutions to information overload in ICT-based systems, using knowledge management systems as a model (Moreno-Llorena \& Alamán, 2006; MorenoLlorena 2008). SKC uses for this purpose some hidden aspects of such systems, as the residual energy of their activity, and properties of both the elements and the activities involved (see the chapter about this prototype in the book).

\section{Conclusion and future work}

In this paper, the KnowCat (acronym for "Knowledge Catalyser") system is presented. KnowCat deals with knowledge in evolution and its main contribution is a Knowledge Crystallisation mechanism, which is supported by virtual communities of experts. This mechanism maintains in the KnowCat knowledge areas the collective accepted knowledge by its user community.

There is a crystallisation process for each knowledge element that can receive user interactions in the community knowledge areas: documents, annotations, version documents and topics. In the case of documents, each document has a social acceptation degree (a value between $0-1,1$ is the maximum value), which takes into account: i) explicit received opinions (i.e. the received votes and how theses votes have been received; and the received assessments, notes and their types); ii) implicit received opinions (i.e. accesses to the document) and iii) its evolution through several document versions. A document, which have enough social acceptation during a determinate period of time, may "crystallise". Therefore, its author wil become and expert in the topic where the document is located.

The annotations receive votes, which can be "in favour" or "against" the annotation. The knowledge crystallisation mechanism calculates per annotation the number of the received 
votes of each type and determinates its social acceptation. A social accepted annotation can "stay" in the knowledge area.

Documents' versions receive votes about the content continuity (i.e. if the new document version deals the content of the previous one in a similar way) and the content improvement (if the new document is an improvement of the previous one). When a document version has social acceptation about the content continuity then it replaces the previous one, i.e., the new document version "consolidate". The social acceptation about the content improvement is used to calculate an specific part of the social acceptation degree of the corresponding document: the part related with its evolution through several document versions.

KnowCat has been tested for twelve years in several research studies with student communities at several universities. These research studies have corroborated the KnowCat design hypotheses and the details of these studies and their results are a great contribution of this research work (Alamán \& Cobos, 1999; Cobos \& Alamán, 2002; Cobos, 2003; Cobos \& Pifarré, 2008; Diez \& Cobos, 2007; Gómez, Gutiérrez, Cobos \& Alaman, 2001; Pifarré \& Cobos, 2009; Pifarré \& Cobos, 2010).

The system was extended with: i) awareness services, which provide users useful information about how they are interacting with the system and supports users to be aware of their collaborative interactions with the system (Cobos, Claros \& Moreno-Llorena, 2009) and ii) a motivation booster service, which provide users feedback information about its work progress in KnowCat and supports to maintain user motivation to interact with the system (Echeverria \& Cobos, 2010).

An interesting open research issue is the integration of KnowCat with other Web platforms or Knowledge Management systems. A first effort in this directions is an initial version of the integration of KnowCat and another Knowledge Management system called Sofia (Cobos, et.al., 2010). Sofia system provides the ability to externalize tacit knowledge, through the group storytelling approach and it has been developed at Federal University of Rio de Janeiro (Luz, et.al., 2008). This integration proposal supports both tacit and explicit knowledge management thanks to the characteristics and functionalities of both systems.

Finally, the KnowCat system is in evolution, furthermore more research studies are planned, both with new user communities and with some of the communities that have used it in previous academic years.

\section{Acknowledgment}

This research was partly funded by the Spanish National Plan of $\mathrm{R}+\mathrm{D}$, project numbers: TIN2008-2081/TIN and TIN2011-24139; by the CAM (Autonomous Community of Madrid), project number: S2009/TIC-1650.

\section{References}

Alamán, X., Cobos, R. (1999). KnowCat: a Web Application for Knowledge Organization. In: LNCS 1727, Chen, P.P., et al. (Eds.), pp. 348-359, Springer, ISSN 0302-9743.

Berners-Lee, T. (1996). The World Wide Web: Past, Present and Future. September, 2011. Available from: <http://www.w3.org/People/Berners-Lee/1996/ppf.html>.

Cobos, R. Alamán, X. (2002). Creating e-books in a distributed and collaborative way. Journal of Electronic Library on Electronic book for Education, Vol. 20, No. 4, (May 2002), pp. 288-295, ISSN 0264-0473. 
Cobos, R. (2003). Mechanisms for the Crystallisation of Knowledge, a proposal using a collaborative system. Doctoral dissertation. Universidad Autónoma de Madrid.

Cobos, R., Pifarré, M. (2008). Collaborative knowledge construction in the web supported by the KnowCat system. Computers \& Education, Vol.50, No. 3, (April 2009), pp. 962978, ISSN 0360-1315.

Cobos, R., Claros, I., Moreno, J. (2009). A proposal of Awareness Services for the Construction of Quality Community Knowledge supported by the Knowledge Management system KnowCat. Proceedings of International Conference Human-Computer Interaction, pp. 365-374, ISBN 978-3-642-02555-6, San Diego, USA, July 19-24, 2009.

Cobos, R., Cajías, R., Barros, L., Borges, M.R.S. (2010). Towards the Construction of a Knowledge Building Environment. LNCS 6240, Luo, Y. (Ed.), pp. 27-30. Springer, ISSN 0302-9743.

Díez, F, Cobos, R. (2007). A Case Study of a Cooperative Learning Experience in Artificial Intelligence. Journal Computer Applications in Engineering Education. Vol. 15, No. 4, (december 2007), pp. 308-316, ISSN 1061-3773.

Echeverria, 1., Cobos, R. (2010). A Motivation Booster proposal based on the monitoring of users' progress in CSCL environments. Proceedings of the 2010 14th International Conference on Computer Supported Cooperative Work in Design (CSCWD 2010), pp. 671676, ISBN 978-1-4244-6763-1, Shanghai, China, April 14-16, 2010.

Gómez, M., Gutiérrez, A., Cobos, R., Alamán, X. (2001). Collaborative Learning with computer-based support in the design of material for the development of abstract thought in Preschool Education. An Experiment in the teaching of mathematics. Proceedings of the International Symposium of Computers in Education 2001, pp. 241-254.

Gross, B. M. (1964). The Managing of Organizations: The Administrative Struggle (Vol. 1), New York: Free Press of Glencoe.

Luz, C.M., Borges, M.R.S., Campos, M.L.M. (2008) Sofia - A framework for the Development of Group Storytelling Tools, Proceedings of the ACM Workshop on Story Representation, Mechanism and Context (SRMC 2008), pp. 41-47, ISBN 978-1-60558315-0, ACM Press, Vancouver, Canada, October 31, 2008.

Moreno-Llorena, J., Alamán, X. (2006). A Proposal of Design for a Collaborative Knowledge Management System by means of Semantic Information. In: HCI related papers of Interacción 2004, Navarro-Prieto, R. et al. (Eds.), Springer, pp. 307-319, 2005. ISBN 978-1-4020-4204-1, Dordrecht, The Netherlands.

Moreno-Llorena, J. (2008). Collaborative Knowledge Management By Means Semantic Information. Doctoral dissertation. Universidad Autónoma de Madrid.

Pifarré, M., Cobos, R. 2009 Evaluation of the Development of Metacognitive Knowledge Supported by the KnowCat system. Educational Technology Research and Development Journal (ETRED), Vol. 57, No. 6 (March 2009), pp. 787-799. ISSN 1042-1629.

Pifarré, M., Cobos, R. 2010. Promoting Metacognitive Skills through peer scaffolding in a Collaborative Learning Computer-based environment. International Journal of Computer-Supported Collaborative Learning, Vol. 5, No. 2, (March 2010), pp. 237-253. ISSN 1556-1607.

Schlichter, J., Koch, K. \& Chengmao, X. (1998). Awareness The Common Link Between Groupware and Communityware. In : Community Computing and Support Systems, T. Ishida (Ed), pp. 77-93, Springer Verlag, ISBN 3-540-65475-5, London, UK. 


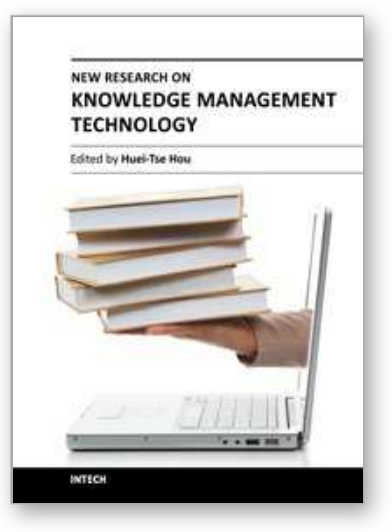

\author{
New Research on Knowledge Management Technology \\ Edited by Dr. Huei Tse Hou
}

ISBN 978-953-51-0074-4

Hard cover, 228 pages

Publisher InTech

Published online 24, February, 2012

Published in print edition February, 2012

Due to the development of mobile and Web 2.0 technology, knowledge transfer, storage and retrieval have become much more rapid. In recent years, there have been more and more new and interesting findings in the research field of knowledge management. This book aims to introduce readers to the recent research topics, it is titled "New Research on Knowledge Management Technology" and includes 13 chapters. In this book, new $\mathrm{KM}$ technologies and systems are proposed, the applications and potential of all KM technologies are explored and discussed. It is expected that this book provides relevant information about new research trends in comprehensive and novel knowledge management studies, and that it serves as an important resource for researchers, teachers and students, and for the development of practices in the knowledge management field.

\title{
How to reference
}

In order to correctly reference this scholarly work, feel free to copy and paste the following:

Ruth Cobos (2012). Knowledge Crystallisation Supported by the KnowCat System, New Research on Knowledge Management Technology, Dr. Huei Tse Hou (Ed.), ISBN: 978-953-51-0074-4, InTech, Available from: http://www.intechopen.com/books/new-research-on-knowledge-management-technology/knowledgecrystallisation-supported-by-the-knowcat-system

\section{INTECH}

open science | open minds

\section{InTech Europe}

University Campus STeP Ri

Slavka Krautzeka 83/A

51000 Rijeka, Croatia

Phone: +385 (51) 770447

Fax: +385 (51) 686166

www.intechopen.com

\section{InTech China}

Unit 405, Office Block, Hotel Equatorial Shanghai

No.65, Yan An Road (West), Shanghai, 200040, China

中国上海市延安西路65号上海国际贵都大饭店办公楼 405 单元

Phone: +86-21-62489820

Fax: +86-21-62489821 
(C) 2012 The Author(s). Licensee IntechOpen. This is an open access article distributed under the terms of the Creative Commons Attribution 3.0 License, which permits unrestricted use, distribution, and reproduction in any medium, provided the original work is properly cited. 